\title{
The functional method: experience from the Robert Debré Hospital
}

\author{
Philippe Souchet ${ }^{1}$, Jean-Pierre Delaby ${ }^{2}$, Matthieu Campana $^{1}$, Jason Chinnappa ${ }^{1}$, Brice Ilharreborde ${ }^{1}$, \\ Anne-Laure Simon ${ }^{1 \wedge}$
}

${ }^{1}$ Department of Pediatric Orthopaedic Surgery, Robert Debré University Hospital, Assistance Publique-Hôpitaux de Paris (AP-HP), Paris University, Paris, France; ${ }^{2}$ Department of Functional Rehabilitation, Robert Debré Hospital, Assistance Publique-Hôpitaux de Paris (AP-HP), Paris University, Paris, France

Contributions: Conception and design: P Souchet, B Ilharreborde; (II) Administrative support: M Campana, AL Simon; (III) Provision of study materials or patients: P Souchet, JP Delaby; (IV) Collection and assembly of data: J Chinnappa; (V) Data analysis and interpretation: AL Simon; (VI) Manuscript writing: All authors; (VII) Final approval of manuscript: All authors.

Correspondence to: Dr. Anne-Laure Simon. Department of Pediatric Orthopaedic Surgery, Robert Debré University Hospital, Assistance Publique des Hôpitaux de Paris (AP-HP), Paris University, 48 Bd Sérurier, 75019 Paris, France. Email: annelaure_simon@hotmail.com.

Background: In the 1970s a conservative treatment for clubfoot (CF) deformity based on daily physiotherapy combining specific sequences was developed: the French functional method (FFM). Over time, the FFM technique has improved and additional measures have been introduced. The aim of this study was to report mid-term and long-term results of clubfeet treated conservatively by the FFM at birth.

Methods: All patients consecutively treated for clubfoot by the FFM between 1993 and 2010 were prospectively included. Initial severity was assessed by the Dimeglio classification. All patients were followed up by the same treating surgeon until skeletal maturity. Final assessment was performed using the International Clubfoot Study Group evaluation system (ICFSG).

Results: A total of 779 feet were included. Surgery was required in $41 \%$ of cases (mean age $2.0 \pm 0.1$ years). The incidence of surgery significantly decreased after the introduction of percutaneous Achilles tenotomy (PAT) in 2000 (63.4\% vs. 29.6\%). At latest evaluation (mean follow-up $12 \pm 0.2$ years), 86\% of patients had excellent or good outcomes (mean ICFSG was $1.83 \pm 0.1$ ). Mean ankle dorsiflexion was $10^{\circ}$ in nonidiopathic $\mathrm{CF}$ and $12.1^{\circ}$ in idiopathic CF. Eleven percent of the idiopathic clubfeet exhibited decreased ankle function $\left(0-10^{\circ}\right)$. There were no cases of overcorrection into excess ankle dorsiflexion or rocker bottom foot deformities.

Conclusions: Current team was the funding institution of the FFM and several modifications were proposed over times to improve outcomes. Eighty-six percent of feet had excellent to good outcomes according to the ICFSG score, with minimal residual deformities (ankle dorsiflexion between $0^{\circ}$ and $10^{\circ}$, calcaneal-thigh angle between $10^{\circ}$ and $20^{\circ}$ ) or insufficient radiological correction (defined by talo-calcaneal angle between $10^{\circ}$ and $20^{\circ}$ ) at latest follow-up.

Keywords: Clubfoot (CF); physiotherapy; French functional method (FFM); conservative treatment

Submitted Nov 29, 2020. Accepted for publication Feb 24, 2021.

doi: $10.21037 /$ atm-20-7727

View this article at: http://dx.doi.org/10.21037/atm-20-7727

^ ORCID: 0000-0001-5562-7812. 


\section{Introduction}

In the 1970s Professor Henri Bensahel and the physiotherapist André Guillaume developed a conservative treatment for clubfoot (CF) deformity based on daily physiotherapy sessions, to ensure very progressive and painless correction, combining specific sequences: the French functional method (FFM) $(1,2)$. The chronology of each manipulation follows the same rationale as the Ponseti method (PM): (I) talo-navicular joint reduction followed by (II) calcaneo-forefoot unit (CFU) lateral derotation $(3,4)$. However, unlike the acute plaster corrections in each stage of the PM, each daily manipulation in the FFM is performed progressively, with specific added focus on triceps surae stretching to improve tibio-talar joint function (5).

With time, the FFM technique has improved and additional measures have been introduced. Firstly, the percutaneous Achilles tenotomy (PAT) which is not routinely performed, unlike the $\mathrm{PM}(6,7)$. This procedure is carried out at walking age to increase tibio-talar range of motion if the Achilles tendon is very tight, defined by tibio-talar dorsiflexion being less than $10^{\circ}$. Secondly, above knee casts using semi-rigid tapes and/or Perlstein leather night bracing have been adopted to treat mild residual deformities (ankle dorsiflexion between $0^{\circ}$ and $10^{\circ}$, calcaneal-thigh angle between $10^{\circ}$ and $20^{\circ}$, dynamic cavus and/or adduction) and avoid recurrences. Finally, the FFM philosophy also includes the "à la carte" soft-tissue release (STR) performed if residual radiological deformities (talocalcaneal angle $\leq 0^{\circ}$ ) persist or relapse after the walking age $(8,9)$. Indeed, in CF management, no deformity should be tolerated to ensure complete correction and function at skeletal maturity. The aim of this study was to report midterm and long-term results of consecutive clubfeet treated conservatively by the FFM using clinical, functional and radiological outcomes based on a specific clubfoot scoring system (International Clubfoot Study Group). We present the following article in accordance with the STROBE reporting checklist (available at http://dx.doi.org/10.21037/ atm-20-7727).

\section{Methods}

\section{Patients}

All patients consecutively treated for clubfoot by the FFM between 1993 and 2010 were prospectively included. The patients were followed up by the same senior surgeon in a single institution since their first month after birth, with a minimum of 5 -year follow-up. Both idiopathic and non- idiopathic clubfeet were included as we use the FFM to treat both types of clubfeet. All patients presenting more than one month after birth or with another initial management were excluded.

The study was conducted in accordance with the Declaration of Helsinki (as revised in 2013). Ethics approval for the study was obtained by the institutional review board (2012-75) and informed consent was taken from all patients.

\section{Guidelines for the FFM}

The FFM is supposed to be performed by FFM-trained physiotherapists because the treatment follows very specific guidelines, similar to the PM, adjusted to each patient according to the severity of the deformity (5). These physiotherapists learned the technique from the initial team that developed the technique (10). However, the FFM is also performed by non FFM-trained physiotherapists (5). All manipulations and immobilizations must be performed progressively and cautiously, to avoid adverse effects such as midfoot breaks. Finally, complementary immobilizations (strapping, above the knee splints and leather night brace) are only performed to maintain the achieved correction between sessions and do not intend to correct any deformity, or force any correction.

The objective of the $1^{\text {st }}$ phase of manipulations is to obtain correct talo-navicular joint reduction (anatomical position of the navicular bone without talar head over coverage) by stretching the antero-medial side of the foot (abductor hallucis) and the plantar aponeurosis (Figure 1). Plantar aponeurosis is stretched by using direct massage manipulation of the sole beneath the $1^{\text {st }}$ metatarsal with the thumb while maintaining forefoot supination. As long as the navicular is not correctly aligned with the talar head, it is impossible to obtain true correction of mid-foot adduction and lateral derotation of the calcaneo-forefoot unit (CFU). The $2^{\text {nd }}$ phase starts after accurate reduction of the talonavicular joint, with the objective of correcting remaining $\mathrm{CFU}$ varus and medial rotation (Figure $1 \mathrm{~B}$ ). At this step, ankle dorsiflexion is still not possible as the CFU and talus axial correction is not complete (talo-calcaneal angle $<20^{\circ}$ ). The objective of the $3^{\text {rd }}$ phase is the progressive and careful sagittal plane re-entry of the talus into the tibio-fibular unit (Figure 1C). Premature ankle dorsiflexion movement must still be avoided, because of the risk of mid-foot rocker bottom deformity (Figure 2A) and anterior concave deformity of the distal tibia physis (Figure 2) (11). The naviculo-cuneiform- 

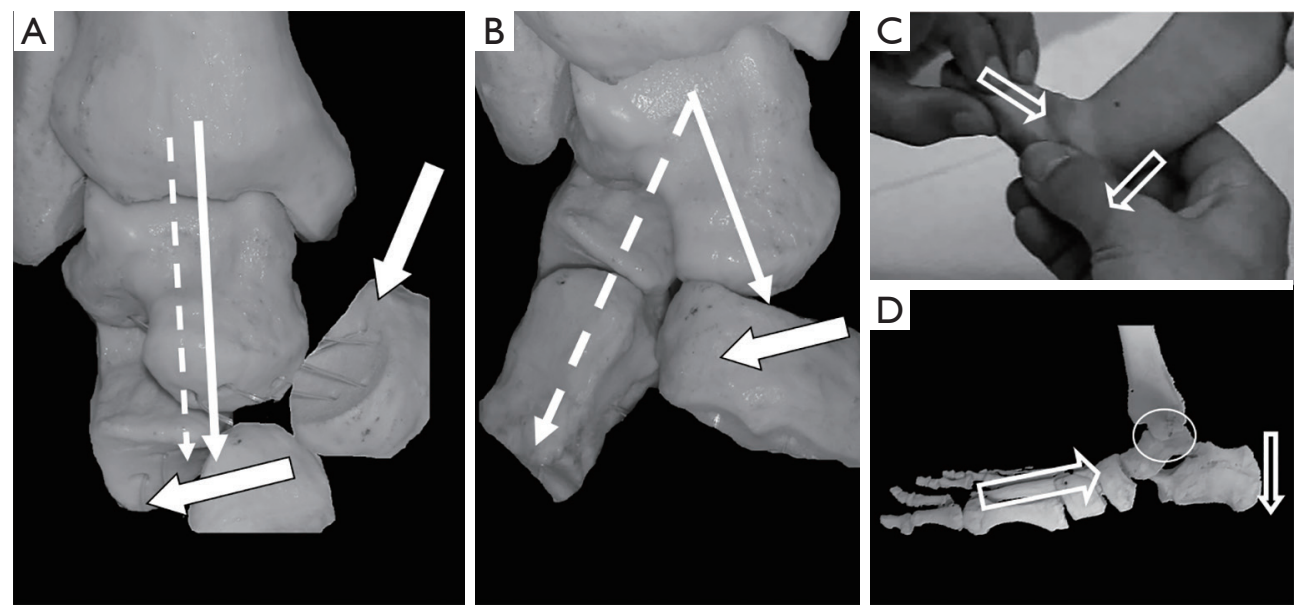

Figure 1 Illustration of the 4 FFM phases: (A) talo-navicular joint reduction (B) derotation of the calcaneo-forefoot unit; (C) re-entry of the CFU and talus into the tibio-fibular unit and (D) restoration of ankle dorsiflexion. FFM, French functional method; CFU, calcaneo-forefoot unit.
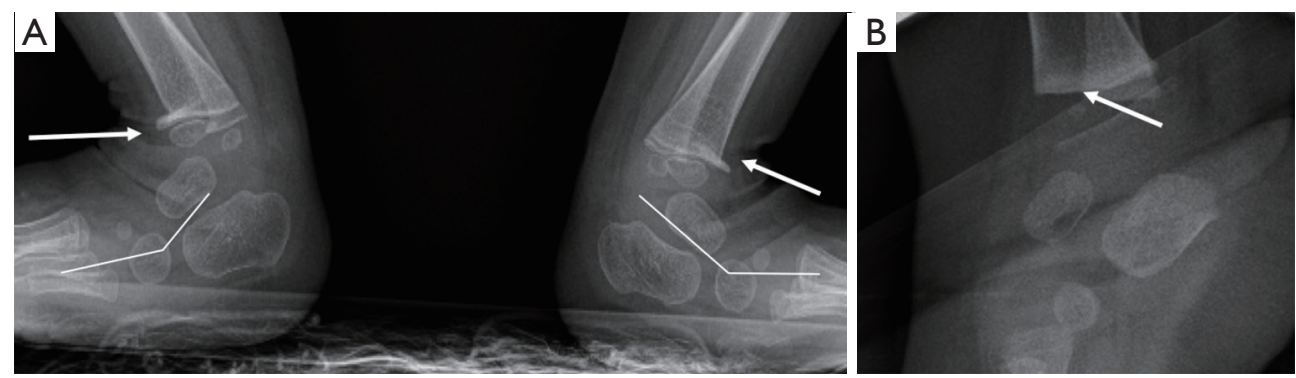

Figure 2 Two cases of distal tibia deformities: (A) acute deformity (rocker bottom deformity and distal tibia deformity) after PAT in a 6-week baby treated with the PM before being referred to our institution; (B) chronic convex deformity of the growth plate induced by the lack of ankle dorsiflexion after walking age in a 12-month-old child (FFM). FFM, French functional method.

$1^{\text {st }}$ metatarsal column is smoothly pushed posteriorly into the talus so that the latter will be progressively reintegrated into the tibio-fibular unit. It should be noted that the talar dome at this phase cannot be deformed by any manipulation (FFM) or immobilization (PM) because it is still anterior to the sagittal axis of the ankle mortise. The final objective during the $4^{\text {th }}$ phase, is to restore the ankle function by stretching the triceps surae for the correction of any remaining equinus if possible (Figure 1D).

\section{Additional measures to the FFM}

Between daily sessions (5 days a week), children under 3 months of age are strapped by the physiotherapist in unforced lateral leg rotation (Figure 3). Between 3 months and walking age, sessions are performed 3 days a week and above knee full-time casts are routinely applied by the orthopaedic surgeon or the physiotherapist using semirigid synthetic material (Soft Cast, 3M, France), moulded in lateral rotation without forcing the forefoot into dorsiflexion (Figure 4). The aim is to maintain or increase the radiographic talocalcaneal angle whilst limiting equinus and cavus deformities. From walking age until 2 years old, sessions are performed once a week. Since 2000, we also utilise an additional PAT procedure at walking age, which is only indicated in cases of persisting equinus with a thick and tight Achilles tendon at physical examination. The procedure is performed by the surgeon, under general anaesthesia with an 18-Gauge needle, followed by one month of long-leg cast immobilization (7). PAT is not performed before this age in order to reduce the risk of recurrences, in contrast to the original PM $(3,6,12)$. At this age, with or without PAT being required, external rotators and eversion are stimulated by ski 

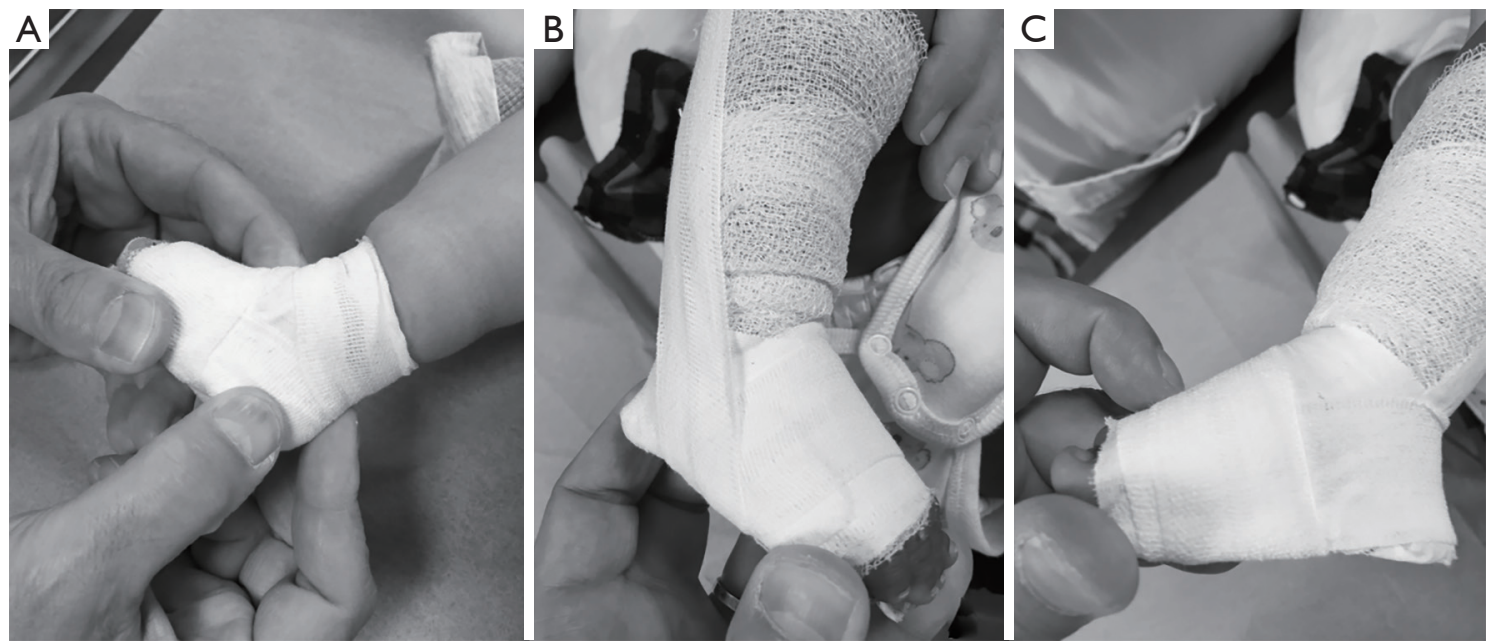

Figure 3 Lateral rotation strapping performed before 3-month of age to maintain the correction obtained during the physiotherapy sessions: (A) lateral view of a 2-month-old boy showing neutral position of the calcaneus with protection of the mid-foot (4th phase); (B) threequarter view and (C) lateral-view of a 1-month-old girl showing lateral traction with the elastic tape for the varus correction. The equinus is still not completely corrected (2nd phase).
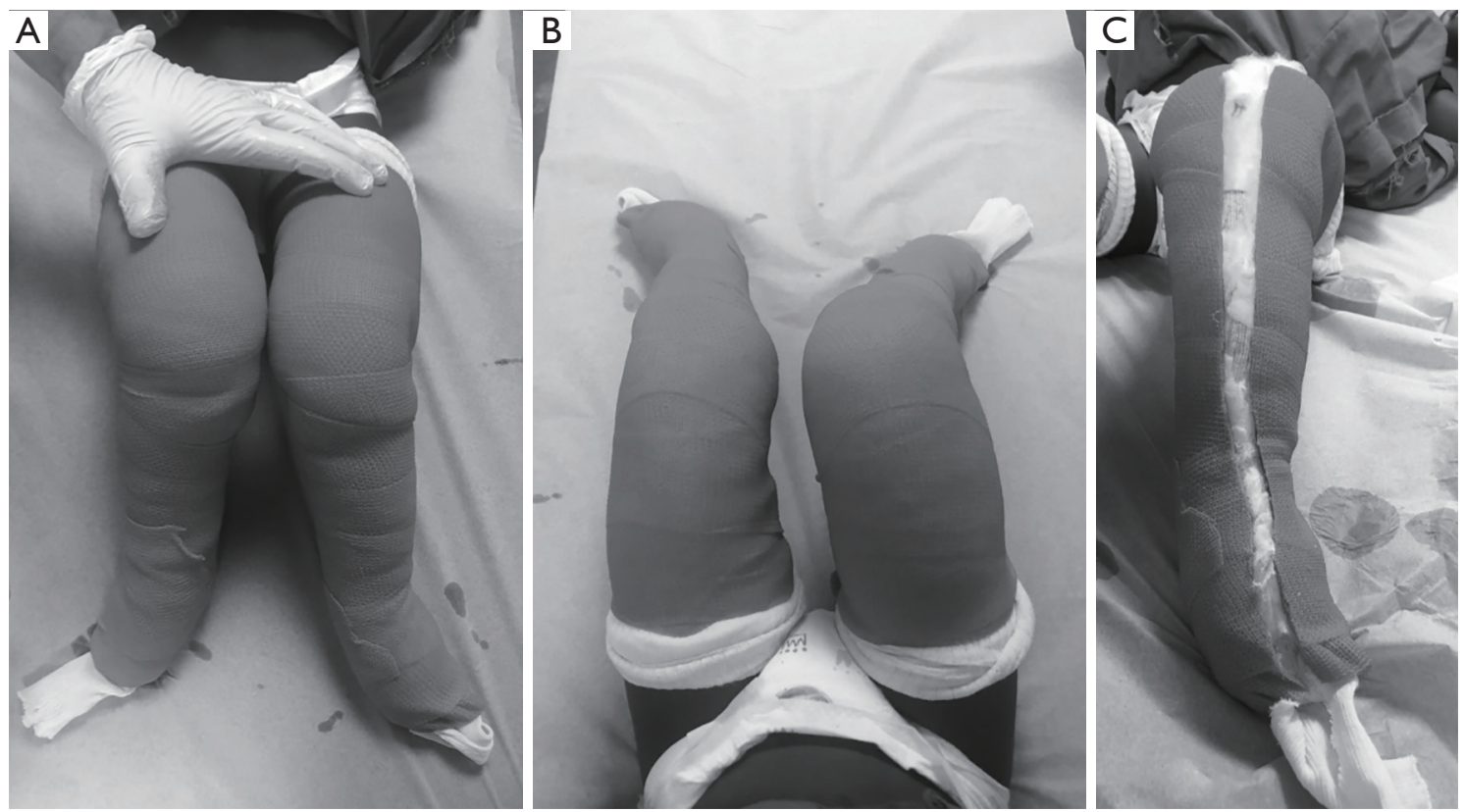

Figure 4 Above knee semi-rigid long-leg casts into lateral rotation in a 9-month-old girl without walking abilities (A) frontal view and (B) view from above, showing a persisting equinus. Semi-rigid casts are removed $(\mathrm{C})$ before bathing and are maintained with self-adhesive tape wrapped around the cast.

walking during weekly sessions (Figure 5 and Video 1). Between the age of 2 and 3 years old, physiotherapy is performed once or twice a month, depending on the amount of tibio-talar joint mobility. Until 3 years old, above the knee sleep-time semi-rigid casts, are applied by the surgeon in cases of insufficient radiographic talocalcaneal angle $\left(10^{\circ}-20^{\circ}\right)$ or if the foot has a tendency to medial rotation (Figure 6). These semi-rigid long-leg 

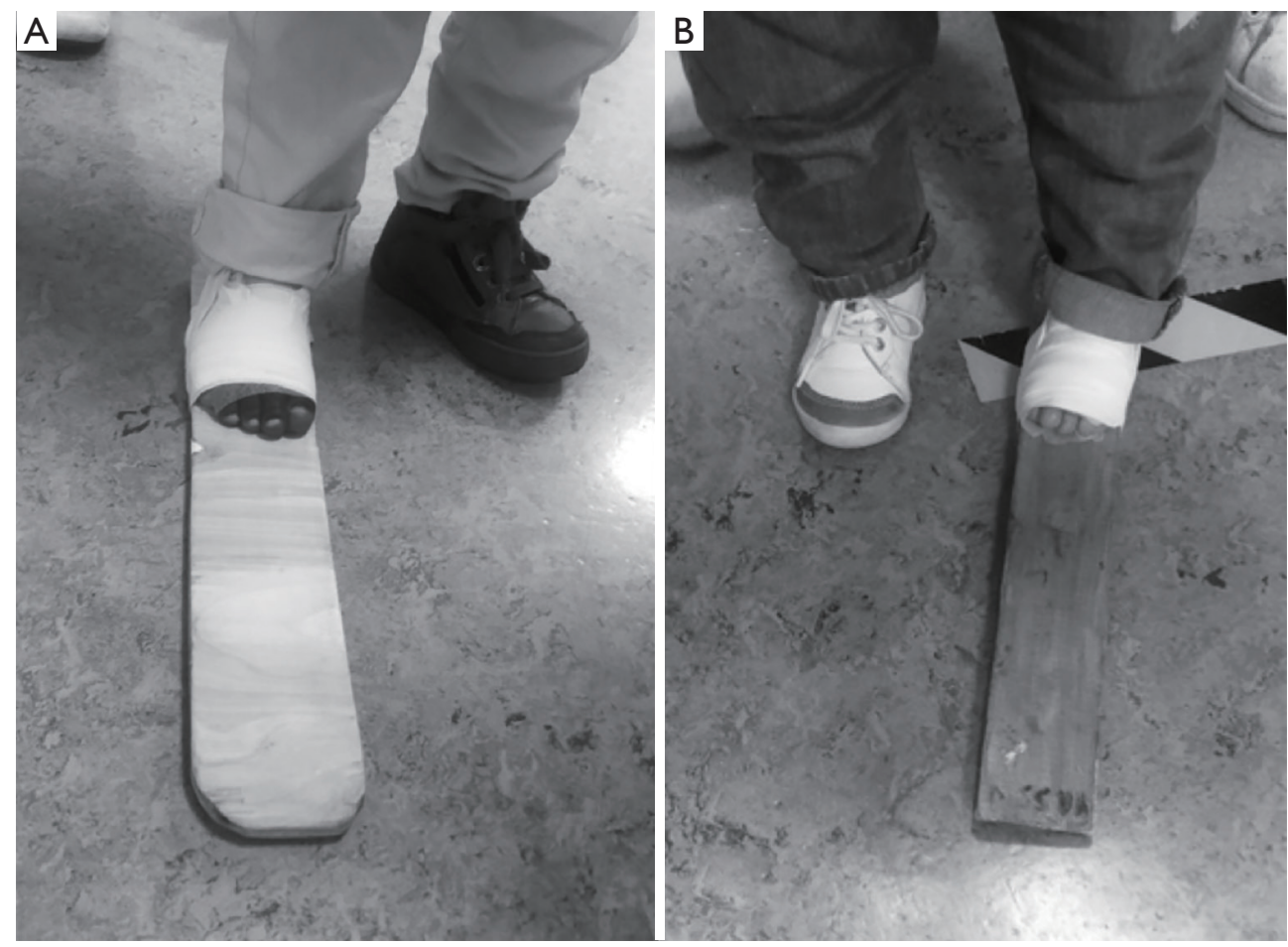

Figure 5 Skis taped around the foot to stimulate external rotation in a 15-month-old boy with a right CF (A) and an 18-month-old boy with left CF (B). It is important to note that both had no residual equinus and PAT was not required. CF, clubfoot; PAT, percutaneous Achilles tenotomy.
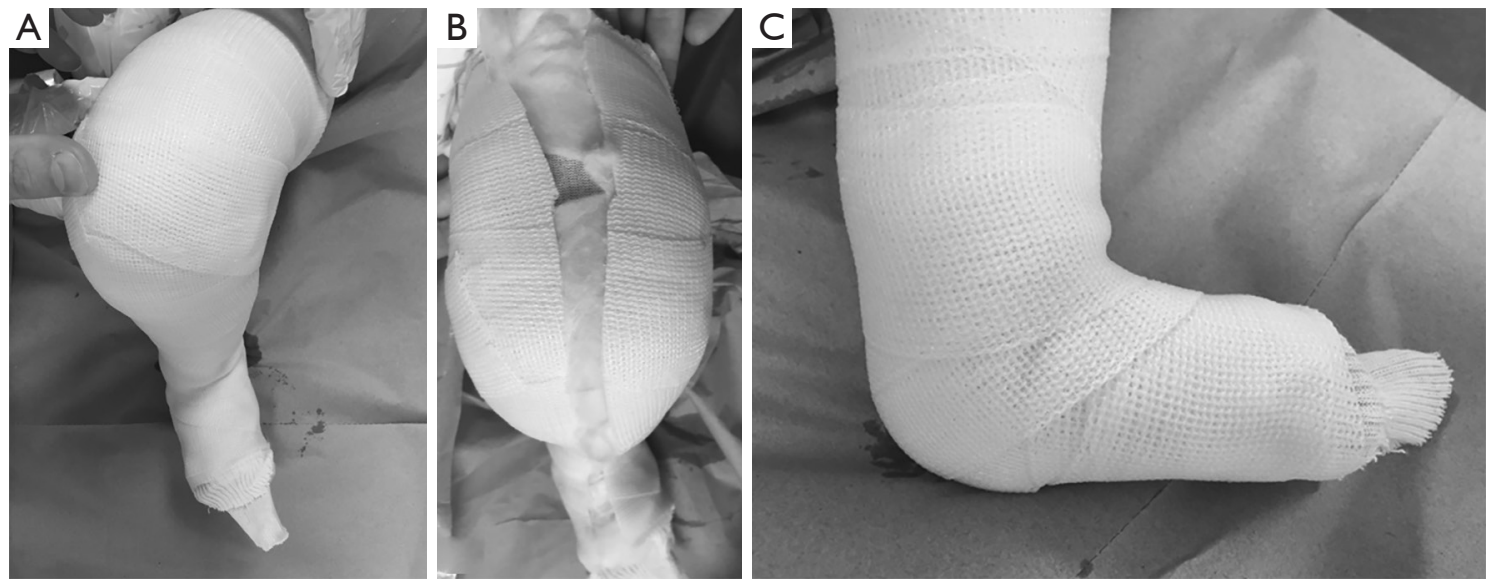

Figure 6 Above knee semi-rigid long-leg cast (A) view from above, (B) frontal view and (C) lateral view performed after walking age to maintain dorsal flexion and avoid cavus deformity in a 14-month-old girl with unilateral CF. Complete correction was obtained by FFM. CF, clubfoot; FFM, French functional method.

casts have similar but not identical function to the Denis Browne splints used in PM $(3,13)$. After the age of 3 years old and until skeletal maturity, night bracing consisting of a Perlstein leather brace may be used in patients with mild residual deformities, such as dynamic antero-medial or medial cavus (forefoot pronation while walking on heels) or limited tibio-talar joint dorsal flexion $\left(0^{\circ}\right.$ to $\left.10^{\circ}\right)$ to reduce the risk of recurrences (Figure 7). 

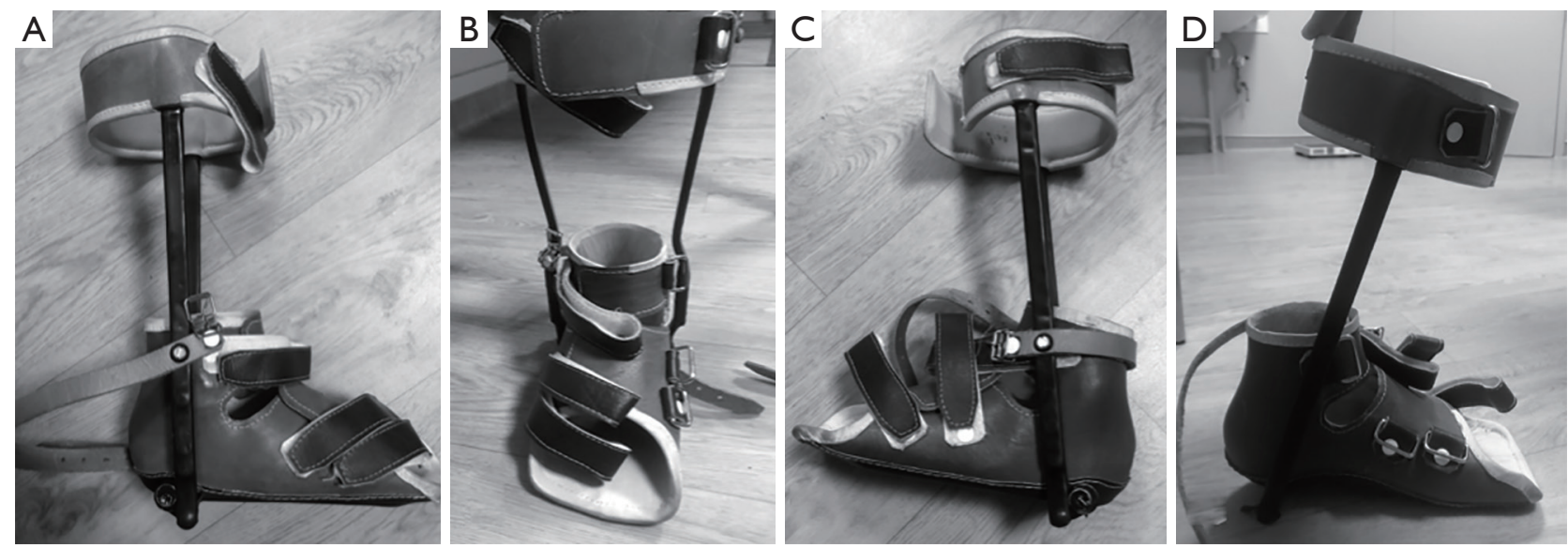

Figure 7 Custom-made Perlstein leather night brace (A) lateral view and (B) frontal view to maintain dorsiflexion and stretch plantar aponeurosis. Lateral and three-quarter views of the Perlstein brace adjusted with $10^{\circ}$ of dorsiflexion $(\mathrm{C}$ and $\mathrm{D})$. The Perlstein brace also molds the forefoot in order to maintain straight hindfoot-forefoot alignment.

\section{When should "à la carte" STR be performed?}

No significant residual deformity should be tolerated in clubfoot management. Despite all the above measures, some feet cannot be fully corrected and an "à la carte" STR, as has been previously described in the literature, might be necessary-i.e., patients with residual deformities or incomplete correction (medial rotation with no correction of the talo-calcaneal angle) $(8,9,14)$. The 2 main keys of "à la carte" STR technique, are to never open the subtalar joint and to never cut the talo-calcaneal ligament to avoid over-correction. Furthermore, flexor hallucis longus and flexor digitorum longus are never lengthened to avoid calcaneus foot deformity.

\section{Initial and final assessment}

Initial and final evaluations were performed by the same senior paediatric orthopaedic surgeon. At first examination after birth, clubfoot severity was assessed by the 20-point Dimeglio classification (15). Patients were classified in 4 groups according to the severity: grade A (1 to 5 points), grade B (6 to 10 points), grade C (11 to 15 points) and grade D (16 to 20 points), 20 points being the most severe foot deformity. Final outcomes were evaluated by the International Clubfoot Study Group (ICFSG) 60-points score (16). Results were classified as excellent [0-4] (no residual deformity), good [5-9] (no residual deformity but mild limitation of ankle dorsal flexion, $0-10^{\circ}$ ), fair $[10-14]$ and poor $\geq 15$ (persisting deformity, joint stiffness, pathological gait) $(9,16)$. The scoring system included morphological, functional and radiological assessments. All children had antero-posterior and lateral views on standing foot radiographs to measure the parameters previously described in the ICFSG scoring system $(9,16)$.

\section{Statistical analysis}

Statistical analyses were performed using SPSS statistics 23.0 (SPSS Inc., Armonk, NY, USA). A Shapiro-Wilk test was performed to assess data distribution. Numeric data were expressed as percentages, means and standard deviation (SD). Statistical comparison used a Student's $t$-test for quantitative variables and a $\mathrm{Chi}^{2}$-test or a Kruskal-Wallis test for qualitative variables. Significance was set at $\mathrm{P}<0.05$.

\section{Results}

\section{Patients}

A total of 546 children, with 779 feet (233 bilateral and 313 unilateral) were included (328 boys and 218 girls). A total of $41 \%$ of feet $(n=320)$ required surgery (mean age at first surgery $2.0 \pm 0.1$ years, $20.4 \%<12$ months) and $11.6 \%$ of these feet required more than one surgical procedure.

Non-idiopathic CF were significantly more severe at birth (mean Dimeglio score $11.8 \pm 0.4$ vs. $10.3 \pm 0.1, \mathrm{P}=0.0005$ ). There were no grade A feet at initial presentation in 
Table 1 Initial assessment at birth using the Dimeglio classification and distribution of the population according to etiology and additional procedures performed

\begin{tabular}{|c|c|c|c|c|c|c|c|c|}
\hline Dimeglio & \multicolumn{2}{|c|}{ Total cohort ( $\mathrm{n}=799$ feet) } & \multicolumn{2}{|c|}{ Non-idiopathic $(\mathrm{n}=85)$} & \multicolumn{2}{|c|}{ PAT $(n=176)$} & \multicolumn{2}{|c|}{$\operatorname{STR}(n=320)$} \\
\hline$A$ & 48 & 6.2 & 4 & 8.3 & 3 & 6.3 & 6 & 12.5 \\
\hline $\mathrm{B}$ & 342 & 43.9 & 29 & 8.5 & 64 & 18.7 & 92 & 26.9 \\
\hline C & 346 & 44.4 & 37 & 10.7 & 97 & 28.0 & 187 & 54.0 \\
\hline$P$ value & \multicolumn{2}{|l|}{ - } & \multicolumn{2}{|c|}{$<10^{5 *}$} & \multicolumn{2}{|c|}{$0.0008^{*}$} & \multicolumn{2}{|c|}{$<10^{5 *}$} \\
\hline
\end{tabular}

Data are expressed as number of feet and percentage according to the stage at initial presentation. ${ }^{*}, \mathrm{P}<0.05$. Dimeglio, Dimeglio classification; PAT, percutaneous Achille tenotomy; STR, soft-tissue release.

Table 2 Data distribution and outcomes in patients with non-idiopathic clubfeet $(\mathrm{n}=85)$

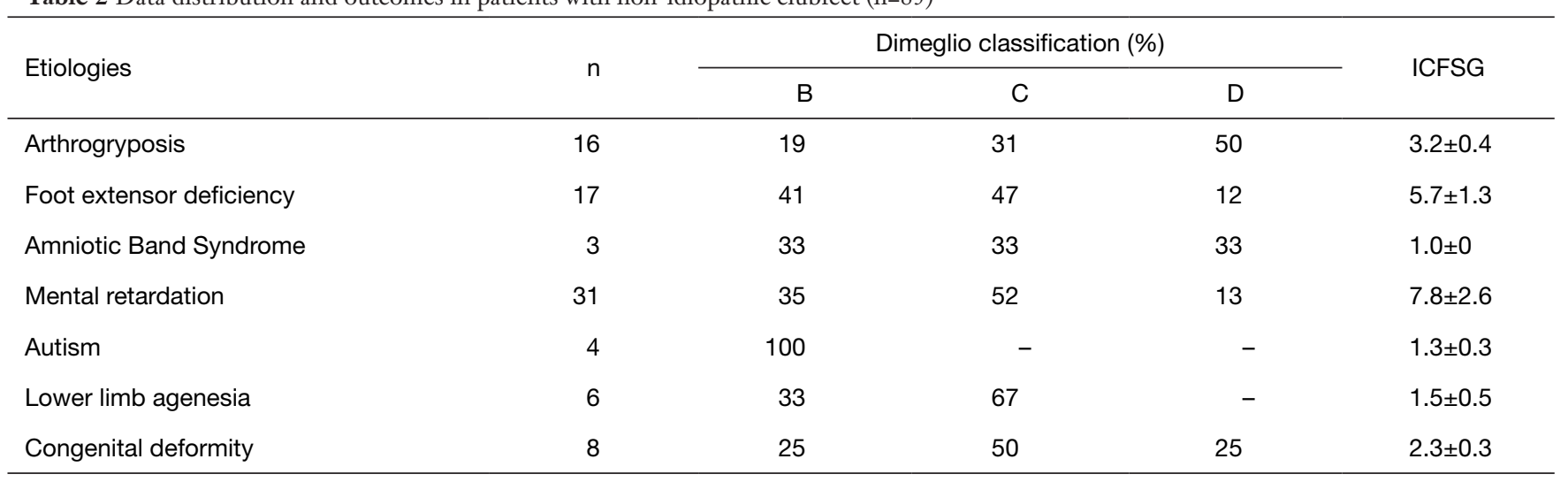

Data are reported in number of feet and percentages except for the ICFSG score (mean \pm SD).

Table 3 Final outcomes according to the ICFSG scoring system

\begin{tabular}{lccc}
\hline ICFSG score & Number of feet $(\mathrm{n}=779)(\%)$ & FFM only $(\mathrm{n}=459)(\%)$ & Feet with surgery $(\mathrm{n}=320)(\%)$ \\
\hline $0-4$ (excellent) & 58.3 & 87.5 & 50.6 \\
$5-9$ (good) & 27.6 & 11.8 & 33.5 \\
$10-14$ (fair) & 12.2 & 0.7 & 13.3 \\
$>14$ (bad) & 1.9 & - & 2.6 \\
\hline
\end{tabular}

*, $\mathrm{P}<0.05$.

the patients with non-idiopathic CF and a significantly higher percentage of grade D feet (Table 1). Variable etiologies (neuromuscular and congenital) were found and mean ICFSG score at final assessment was significantly poorer compared to the idiopathic CF $(7.2 \pm 0.6$ vs. $3 \pm 0.1$, $\mathrm{P}<0.000001$ ) (Table 2). Among non-idiopathic CF, $38.2 \%$ did not require surgery, which was significantly different from idiopathic CF $(62 \%, \mathrm{P}<0.00001)$.

\section{FFM final outcomes}

At latest evaluation (mean follow-up $12 \pm 0.2$ years, from 6 to 26 years), there were $86 \%$ excellent or good outcomes in the global population (Table 3). In patients without surgery ( $\mathrm{n}=459$ feet), mean ICFSG was $1.83 \pm 0.1$ and final outcomes were excellent in $87.5 \%$ and $73 \%$ of grade $\mathrm{A}$ and $\mathrm{B}$ feet respectively. There were only 2 cases of fair results (non- 
Table 4 Final outcomes in the patients without surgery $(\mathrm{n}=459)$ with findings on physical examination, clinical and radiological residual deformity

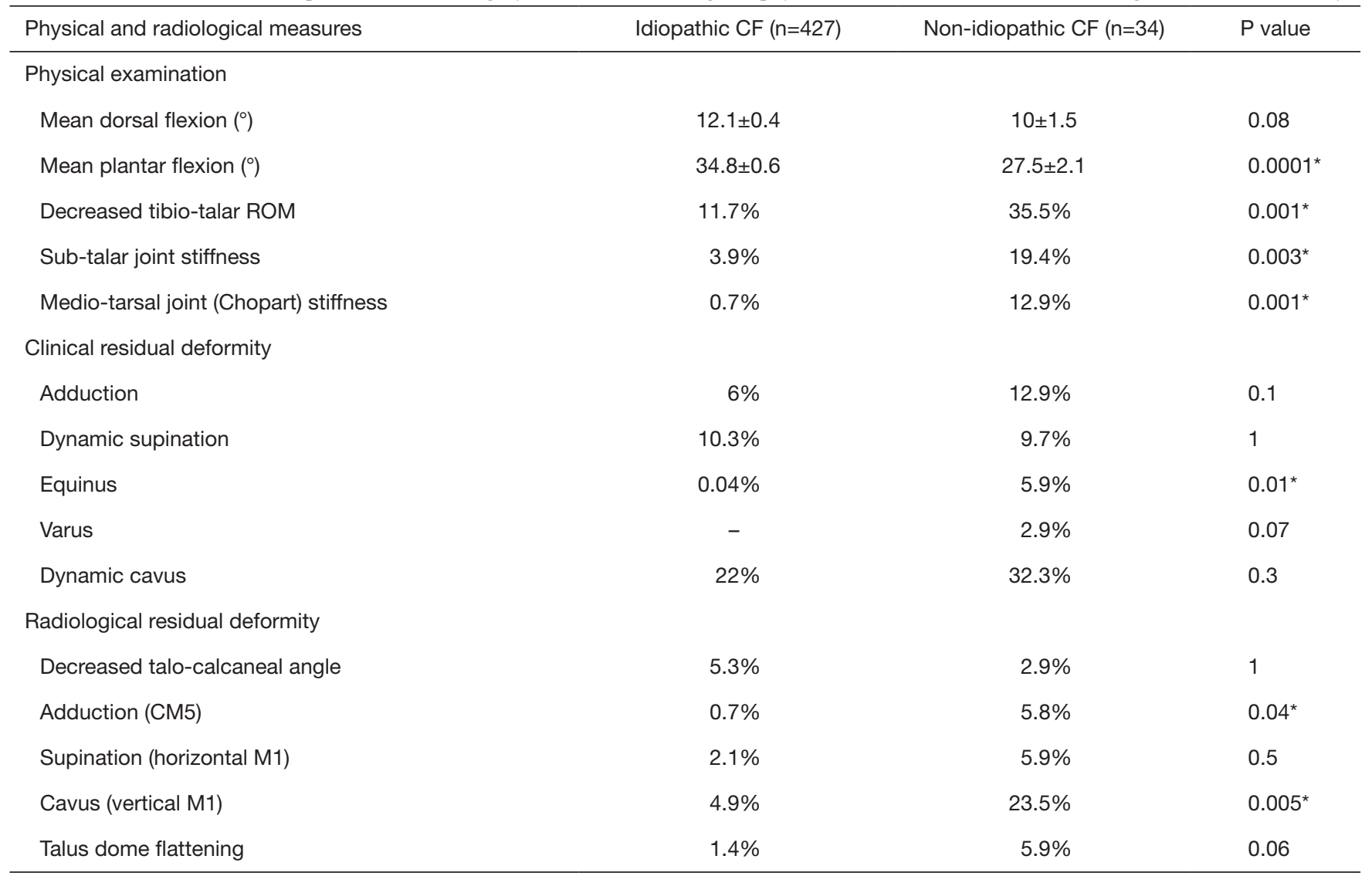

Data are expressed in percentages of feet except for the dorsal and plantar flexion (mean $\pm \mathrm{SD}$ ). *Significant result, $\mathrm{P}<0.05$. CF, clubfoot; ROM, range of motion; CM5, Calcaneo- $5^{\text {th }}$ metatarsal angle; $M 1,1^{\text {st }}$ metatarsal bone.

idiopathic) among the initial grade $\mathrm{C}(\mathrm{n}=159)$ feet and no poor result. The risk of FFM failure with need for STR was significantly higher in Grade D patients (Table 1). Final evaluation found no case of calcaneus foot, or rocker bottom deformity (Table 4). Non-idiopathic CF were significantly more stiff than idiopathic ones. One case of recurrent equinus was found in a patient that was non-compliant with routine follow-up (seen 4 years after scheduled visit).

\section{Influence of the PAT on FFM final outcomes}

The total incidence of PAT was $22.5 \%$ (mean age $20 \pm 1.7$ months) and was mostly performed after 2000 as previously mentioned (Figure 8). PAT significantly decreased the rate of STR after 2000 (63.4\% vs. 29.6\%, $\mathrm{P}<0.00001)$ (Figure 9). Only 5 PAT were performed before 2000 (2 grade B and 3 grade C). PAT was performed 112 times (19.6\%) in the group of patients without STR $(n=459)$, with a significant higher ICFSG score $(2.71 \pm 0.3$ vs. $1.5 \pm 0.1, \mathrm{P}<0.00001)$ compared to the one without PAT, especially for the idiopathic CF (Table 5). In the STR group ( $\mathrm{n}=320)$, PAT was performed prior to STR in $8 \%$ of the patients $(10.5 \%$ for non-idiopathic $\mathrm{CF}$ vs. $7.8 \%$ for idiopathic $\mathrm{CF}, \mathrm{P}=0.4$ ).

\section{Influence of the physiotherapist experience on FFM final outcomes}

A total of $65.2 \%$ CF was managed by FFM-trained physiotherapists, Grade A, B, C and D in respectively $5.9 \%$, $47.8 \%, 40.6 \%$ and $5.7 \%$ of the feet. A significant difference of distribution was found when comparing to non FFMtrained physiotherapists ( $52 \%$ of Grade C, $\mathrm{P}=0.001$ ). A significant greater number of non-idiopathic feet were managed by non FFM-trained physiotherapists $(14.8 \%$ vs. $9.6 \%, \mathrm{P}=0.04)$ and the rate of surgery was also significantly higher in these patients ( $48 \%$ vs. $37 \%, \mathrm{P}=0.002)$. There 


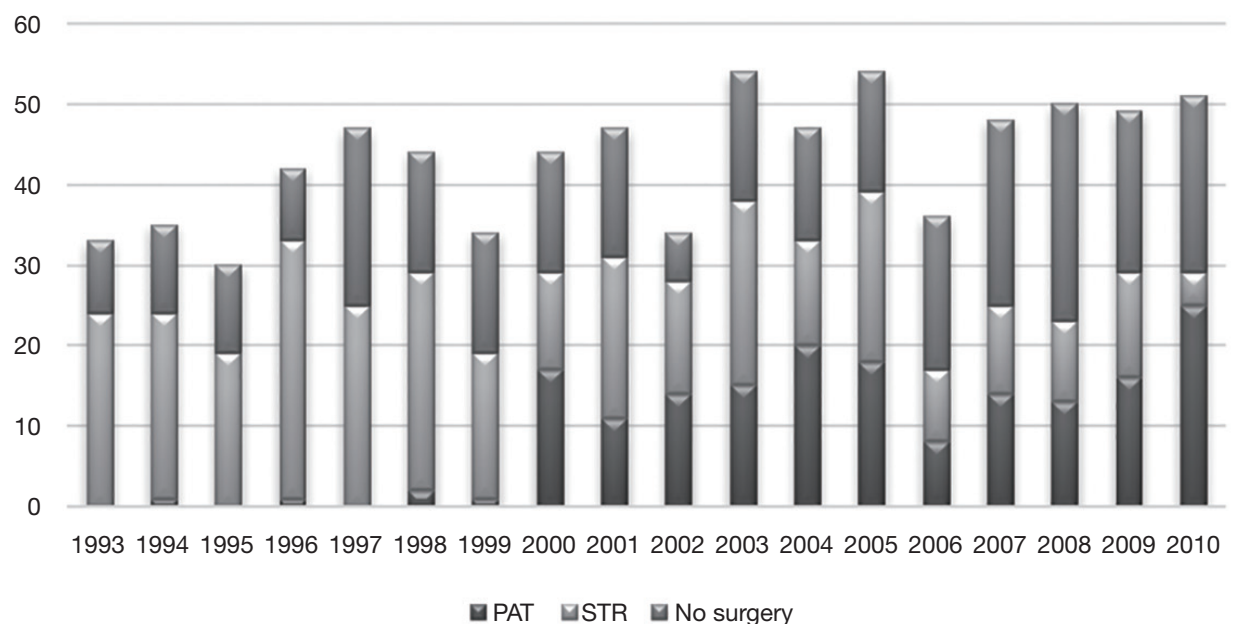

Figure 8 Evolution of the treatments with time among the study population.

Table 5 ICFSG score at final evaluation in the patients without surgery $(n=459)$ according to the need for PAT and the etiology of the clubfoot

\begin{tabular}{|c|c|c|c|c|c|c|c|}
\hline ICFSG & \multicolumn{3}{|c|}{ PAT $(n=112)$} & \multicolumn{3}{|c|}{ No PAT $(n=347)$} & $P$ value \\
\hline Total FFM only cohort & $81 \%$ & $18.8 \%$ & $0.2 \%$ & $91.5 \%$ & $8.5 \%$ & 0 & $0.004^{*}$ \\
\hline$\%$ of non-idiopathic $(n=34)$ & $40 \%$ & $50 \%$ & $20 \%$ & $65 \%$ & $30 \%$ & $5 \%$ & 0.25 \\
\hline$\%$ of idiopathic $(n=427)$ & $82 \%$ & $18 \%$ & - & $92 \%$ & $8 \%$ & - & $0.04^{*}$ \\
\hline
\end{tabular}

Data are expressed in percentage (\%). *Significant difference, $\mathrm{P}<0.05$.

were no significant differences regarding final outcomes in patients without surgery $(\mathrm{n}=459)$ between both FFM trained and non FFM-trained physiotherapists $(1.9 \pm 0.2 v s$. $2.1 \pm 0.2, \mathrm{P}=0.1)$.

\section{Discussion}

Current team was the funding institution of the FFM and several modifications were proposed over times to improve outcomes of this particular CF conservative treatment $(2,10,15)$. With time, several processes have been introduced to constantly improve the technique outcomes, resulting from the constant collaborative effort between the FFM-trained physiotherapists and the surgical team led by our senior foot surgeon.

\section{The influence of additional procedures on the original FFM}

In contrast to the PM that routinely performs PAT between the two last casts, this procedure was not systematically performed in FFM (4,6). The introduction of PAT in 2000 has significantly decreased the need for surgery (Figure 9) (5). The rate of PAT in the current study (22\%) was slightly higher than prior reports on FFM (15\% to $17 \%$ ) and was only performed after children have started to walk to avoid recurrences $(17,18)$. Night immobilization with above knee semi-rigid casts and/ or Perlstein leather braces were also progressively added (after 2010) to the initial FFM concept, with the aim to limit cavus and ankle equinus by stretching the plantar aponeurosis. The literature shows that Denis-Browne splints are more effective than unilateral orthosis, but they have poor compliance (34\% to $61 \%)(19,20)$. Poor compliance or increase recurrences was not found with our splinting regime. However, the causeeffect relationship of these improvements requires further investigation.

\section{Incidence of surgery in the FFM}

The rate of surgery after CF conservative treatment with 


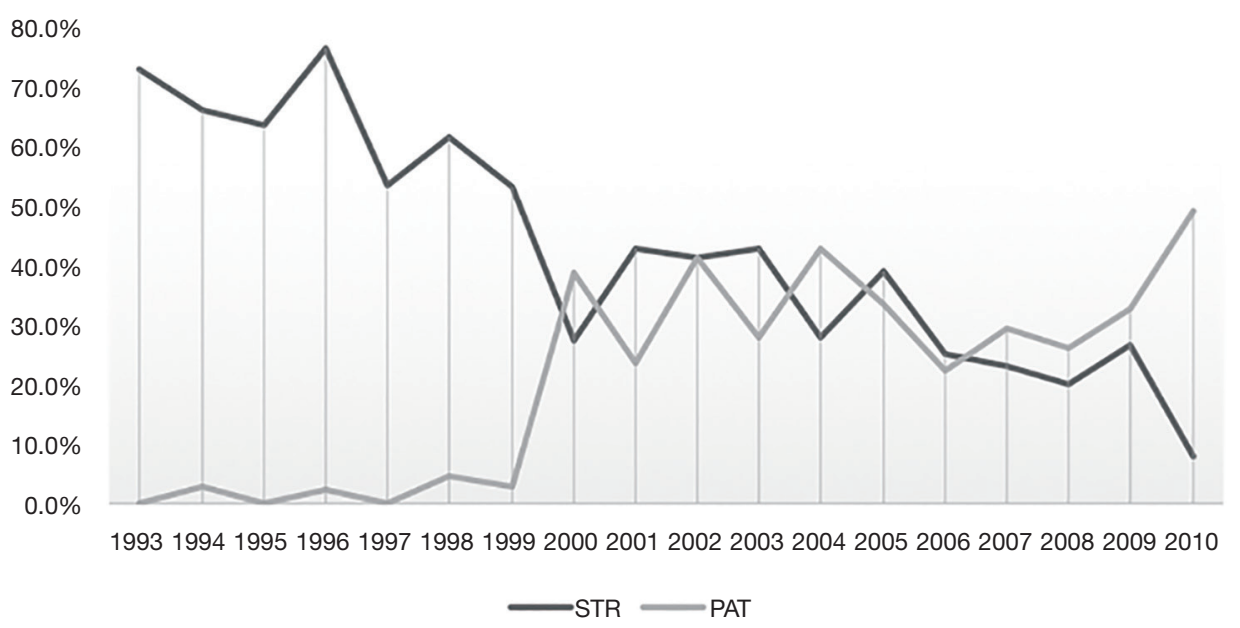

Figure 9 Evolution of the PAT and surgery rates with time showing a significant decrease of the surgery rate after 2000. PAT, percutaneous Achilles tenotomy.

either FFM or PM is very variable in the literature $(1.3 \%$ to $48 \%$ ), however exclusion criteria were not always clearly defined in these reports $(13,17,18,21,22)$. Faulks et al. showed that the rate of surgery tends to be similar in both treatments, the difference being the age at surgery $(23,24)$. The total incidence of "à la carte STR" in the current study, including non-idiopathic CF, was high (41\%). But there was a significant reduction of the surgery rate after the introduction of additional measures. However, our study included all causes of clubfoot deformity. This was done as a reflection of our actual practices and to avoid bias from exclusion of poor or fair results.

Our results are consistent with Jeans et al. (surgery 46\% for FFM vs. 41\% for PM) (17). More recently, Canavese et al. showed excellent results ( $7 \%$ of operative treatment) by combining both conservative methods with a hybrid method (25). This may be an interesting alternative to achieve further progress on clubfoot treatment. It is also important to note that the "à la carte STR" performed in the current institution was based on radiographic findings (talo-calcaneal angle $<10^{\circ}$ ) and is radically different from the Turco procedure, which showed catastrophic results $(8,9,14,26)$. Both procedures should not be mistaken. The "à la carte STR" is based on the same concept of correction of both conservative treatments by targeting only the pathological fibrotic tissues with cautious respect for the foot muscles and tendons $(8,9)$.

\section{Ankle function after FFM}

At latest follow-up, mean dorsiflexion of the ankle joint was $10^{\circ}$ for non-idiopathic $\mathrm{CF}$ and $12.1^{\circ}$ for idiopathic $\mathrm{CF}$, with $11 \%$ of the latter exhibiting decreased ankle function $\left(0-10^{\circ}\right)$ and no cases of overcorrection into excess dorsiflexion (Table 4). These results are consistent with Jeans et al. findings studying both PM and FFM outcomes (17). Careful manipulations by the physiotherapist should theoretically improve ankle function compared with the PM. However, this requires further investigation by objective assessment with gait analysis methods (27-29). In the current study, talar dome flattening was found in the ICF and NICF in respectively $1.4 \%$ and $5.9 \%$, which was significantly lower than Rampal et al. (50\%) (30). No rocker bottom deformity occurred at latest follow-up meaning that the feet were never forced into dorsal flexion $(11,30)$.

\section{Rationale for the FFM "sequelae"}

Dynamic cavus was the most frequent (22\%) mild residual deformity found (Table 4). Perlstein leather braces have been used to avoid the evolution to a fixed deformity requiring surgery but this needs further investigation in future research. Our institution recommends night splint immobilization be maintained until the patient recovers complete dynamic foot function, defined by the ability to walk on heels (active ankle dorsiflexion $>10^{\circ}$ ) without dynamic supination or dynamic cavus (forefoot pronation), which is a different treatment concept compared to the PM (20,31). Persistent forefoot adduction (axial plane deformity), was related to the abductor hallucis muscle hypo-extensibility. Dynamic supination confirmed on 
standing radiographs was rarely found $(2.1 \%$ for ICF and $5.9 \%$ for NICF) and was connected to the excessive work of the tibialis anterior muscle to compensate a lack of ankle dorsal flexion. Finally, fixed supination with a dorsal bunion deformity was not found in the feet without STR. However, this sequela is treated by the modified Lapidus (reverse Jones) procedure in the current institution, which is not always the case in the PM which often prefers tibialis anterior tendon transfer $(32,33)$.

\section{Limitations}

This study has several limitations. The cohort was not comparative with the PM, however the Dallas team has already proven similar results in terms of rates of surgery and final outcomes with the two methods $(18,23,24)$. Our study also reports a single-institution experience that lends itself to methodological and observer bias. However, all the patients primarily treated with the FFM were analyzed, including poor results for non-idiopathic clubfeet to minimize the risk of bias. Further investigations are also required to analyze the contribution of above the knee semi-rigid casts and Perlstein leather braces on FFM final outcomes. Finally, quantitative functional gait analysis is still required for objective assessment as well as inter- and intra-observer agreements for the validation of the ICFSG scoring system. However, to the best of our knowledge, the Laaveg-Ponseti score have also not been validated in the current literature (3).

In conclusion, $86 \%$ of feet had excellent to good outcomes according to the ICFSG score, with minimal residual deformities or insufficient radiological correction at latest follow-up.

\section{Acknowledgments}

Funding: None.

\section{Footnote}

Provenance and Peer Review: This article was commissioned by the Guest Editors (Federico Canavese and Alain Dimeglio) for the series "Clubfoot" published in Annals of Translational Medicine. The article has undergone external peer review.

Reporting Checklist: The authors have completed the STROBE reporting checklist. Available at http://dx.doi. org/10.21037/atm-20-7727
Data Sharing Statement: Available at http://dx.doi. org/10.21037/atm-20-7727

Peer Review File: Available at http://dx.doi.org/10.21037/ atm-20-7727

Conflicts of Interest: All authors have completed the ICMJE uniform disclosure form (available at http://dx.doi. org/10.21037/atm-20-7727). The series "Clubfoot" was commissioned by the editorial office without any funding or sponsorship. Professor Ilharreborde is a consultant for Zimmer-Biomet and Implanet. The authors have no other conflicts of interest to declare.

Ethical Statement: The authors are accountable for all aspects of the work in ensuring that questions related to the accuracy or integrity of any part of the work are appropriately investigated and resolved. The study was conducted in accordance with the Declaration of Helsinki (as revised in 2013). The study was approved by the institutional board of Robert Debré (2012-75) and informed consent was taken from all the patients.

Open Access Statement: This is an Open Access article distributed in accordance with the Creative Commons Attribution-NonCommercial-NoDerivs 4.0 International License (CC BY-NC-ND 4.0), which permits the noncommercial replication and distribution of the article with the strict proviso that no changes or edits are made and the original work is properly cited (including links to both the formal publication through the relevant DOI and the license). See: https://creativecommons.org/licenses/by-nc-nd/4.0/.

\section{References}

1. Bensahel H, Degrippes Y, Billot C. Comments about 600 club feet. Chir Pediatr 1980;21:335-42.

2. Bensahel H, Guillaume A, Czukonyi Z, et al. Results of physical therapy for idiopathic clubfoot: a long-term follow-up study. J Pediatr Orthop 1990;10:189-92.

3. Laaveg SJ, Ponseti IV. Long-term results of treatment of congenital club foot. J Bone Joint Surg Am 1980;62:23-31.

4. Morcuende JA, Weinstein SL, Dietz FR, et al. Plaster cast treatment of clubfoot: the Ponseti Method of manipulation and casting. J Pediatr Orthop B 1994;3:161-7.

5. Souchet P, Bensahel H, Themar-Noel C, et al. Functional treatment of clubfoot: a new series of 350 idiopathic clubfeet with long-term follow-up. J Pediatr Orthop B 
2004;13:189-96.

6. Lebel E, Karasik M, Bernstein-Weyel M, et al. Achilles tenotomy as an office procedure: safety and efficacy as part of the Ponseti serial casting protocol for clubfoot. J Pediatr Orthop 2012;32:412-5.

7. Minkowitz B, Finkelstein BI, Bleicher M. Percutaneous tendo-Achilles lengthening with a large-gauge needle: a modification of the Ponseti technique for correction of idiopathic clubfoot. J Foot Ankle Surg 2004;43:263-5.

8. Bensahel H, Csukonyi Z, Desgrippes Y, et al. Surgery in residual clubfoot: one-stage medioposterior release «à la carte». J Pediatr Orthop 1987;7:145-8.

9. Bocahut N, Simon AL, Mazda K, et al. Medial to posterior release procedure after failure of functional treatment in clubfoot: a prospective study. J Child Orthop 2016;10:109-17.

10. Dimeglio A, Canavese F. The French functional physical therapy method for the treatment of congenital clubfoot. J Pediatr Orthop B 2012;21:28-39.

11. Koureas G, Rampal V, Mascard E, et al. The incidence and treatment of rocker bottom deformity as a complication of the conservative treatment of idiopathic congenital clubfoot. J Bone Joint Surg Br 2008;90:57-60.

12. Ponseti IV. Common errors in the treatment of congenital clubfoot. Int Orthop 1997;21:137-41.

13. Morcuende JA, Dolan LA, Dietz FR, et al. Radical reduction in the rate of extensive corrective surgery for clubfoot using the Ponseti method. Pediatrics 2004;113:376-80.

14. Souchet P, Ilharreborde B, Fitoussi F, et al. Calcaneal derotation osteotomy for clubfoot revision surgery. $\mathrm{J}$ Pediatr Orthop B 2007;16:209-13.

15. Diméglio A, Bensahel H, Souchet $P$, et al. Classification of clubfoot. J Pediatr Orthop B 1995;4:129-36.

16. Bensahela H, Kuo K, Duhaime M, et al. Outcome evaluation of the treatment of clubfoot: the international language of clubfoot. J Pediatr Orthop B 2003;12:269-71.

17. Jeans KA, Karol LA, Erdman AL, et al. Functional Outcomes Following Treatment for Clubfoot: Ten-Year Follow-up. J Bone Joint Surg Am 2018;100:2015-23.

18. Chotel F, Parot R, Seringe R, et al. Comparative study: Ponseti method versus French physiotherapy for initial treatment of idiopathic clubfoot deformity. J Pediatr Orthop 2011;31:320-5.

19. George HL, Unnikrishnan PN, Garg NK, et al. Unilateral foot abduction orthosis: is it a substitute for Denis Browne boots following Ponseti technique? J Pediatr Orthop B
2011;20:22-5.

20. Alves C. Bracing in clubfoot: do we know enough? J Child Orthop 2019;13:258-64.

21. Morcuende JA, Abbasi D, Dolan LA et al. Results of an accelerated Ponseti protocol for clubfoot. J Pediatr Orthop 2005;25:623-6.

22. Chang CH, Wang SM, Kuo KN. The Ponseti Method Decreased the Surgical Incidence in Children with Congenital Clubfoot: A Population-Based, 8 Birth-Year Cohort Study. J Bone Joint Surg Am 2019;101:1955-60.

23. Steinman S, Richards BS, Faulks S, et al. A comparison of two nonoperative methods of idiopathic clubfoot correction: the Ponseti method and the French functional (physiotherapy) method. Surgical technique. J Bone Joint Surg Am 2009;91 Suppl 2:299-312.

24. Faulks S, Richards BS. Clubfoot treatment: Ponseti and French functional methods are equally effective. Clin Orthop Relat Res 2009;467:1278-82.

25. Canavese F, Mansour M, Moreau-Pernet G, et al. The hybrid method for the treatment of congenital talipes equinovarus: preliminary results on 92 consecutive feet. J Pediatr Orthop B 2017;26:197-203.

26. Turco VJ. Resistant congenital club foot--one-stage posteromedial release with internal fixation. A follow-up report of a fifteen-year experience. J Bone Joint Surg Am 1979;61:805-14.

27. Karol LA, Jeans K, ElHawary R. Gait analysis after initial nonoperative treatment for clubfeet: intermediate term followup at age 5. Clin Orthop Relat Res 2009;467:1206-13.

28. Gottschalk HP, Karol LA, Jeans KA. Gait analysis of children treated for moderate clubfoot with physical therapy versus the Ponseti cast technique. J Pediatr Orthop 2010;30:235-9.

29. Mindler GT, Kranzl A, Lipkowski CAM, et al. Results of gait analysis including the Oxford foot model in children with clubfoot treated with the Ponseti method. J Bone Joint Surg Am 2014;96:1593-9.

30. Rampal V, Chamond C, Barthes X, et al. Long-term results of treatment of congenital idiopathic clubfoot in 187 feet: outcome of the functional « French » method, if necessary completed by soft-tissue release. J Pediatr Orthop 2013;33:48-54.

31. Hosseinzadeh P, Kiebzak GM, Dolan L, et al. Management of Clubfoot Relapses With the Ponseti Method: Results of a Survey of the POSNA Members. J Pediatr Orthop 2019;39:38-41.

32. Holt JB, Oji DE, Yack HJ, et al. Long-term results of 
tibialis anterior tendon transfer for relapsed idiopathic clubfoot treated with the Ponseti method: a follow-up of thirty-seven to fifty-five years. J Bone Joint Surg Am 2015;97:47-55.

Cite this article as: Souchet $\mathrm{P}$, Delaby JP, Campana M, Chinnappa J, Ilharreborde B, Simon AL. The functional method: experience from the Robert Debré Hospital. Ann Transl Med 2021;9(13):1098. doi: 10.21037/atm-20-7727
33. Yong SM, Smith PA, Kuo KN. Dorsal bunion after clubfoot surgery: outcome of reverse Jones procedure. J Pediatr Orthop 2007;27:814-20. 